\title{
ESTIMATION OF PM 2.5 VERTICAL DISTRIBUTION USING CUSTOMIZED UAV AND MOBILE SENSORS IN BRGY. UP CAMPUS, DILIMAN, QUEZON CITY
}

\author{
J. B. Babaan ${ }^{1}$, J. P. Ballori ${ }^{1}$, A. M. Tamondong ${ }^{1}$, R. V. Ramos ${ }^{1}$, P. M. Ostrea ${ }^{2}$ \\ ${ }^{1}$ Department of Geodetic Engineering, University of the Philippines - Diliman, Quezon City, Philippines - (jbbabaan, jpballori, \\ amtamondong, rvramos)@up.edu.ph \\ ${ }^{2}$ Eisenpatt Industrial Engineering Services, Las Piñas City, Philippines - patrick.ostrea@ eisenpatt.com
}

KEY WORDS: Unmanned Aerial Vehicle, Air Quality, Quezon City, Monitoring, Particulate matter (PM) Concentration, $\mathrm{PM}_{2.5}$, Meteorological Parameters

\begin{abstract}
:
As the unmanned aerial vehicle (UAV) technology has gained popularity over the years, it has been introduced for air quality monitoring. This study demonstrates the feasibility of customized UAV with mobile monitoring devices as an effective, flexible, and alternative means to collect three-dimensional air pollutant concentration data. This also shows the vertical distribution of PM concentration and the relationship between the $\mathrm{PM}_{2.5}$ vertical distribution and the meteorological parameters within $500 \mathrm{~m}$ altitude on a single flight in UP Diliman, Quezon City. Measurement and mapping of the vertical distribution of particulate matter (PM) 2.5 concentration is demonstrated in this research using integrated air quality sensors and customized Unmanned Aerial Vehicle. The flight covers an area with a radius of 80 meters, following a cylindrical path with 40 -meter interval vertically. $\mathrm{The} \mathrm{PM}_{2.5}$ concentration values are analyzed relative to the meteorological parameters including air speed, pressure, temperature, and relative humidity up to a 500meter-flying height in a single flight in Barangay UP Campus, UP Diliman, Quezon City. The study shows that generally, the $\mathrm{PM}_{2.5}$ concentration decreases as the height increases with an exception in the $200-280 \mathrm{~m}$ above ground height interval due to a sudden change of atmospheric conditions at the time of the flight. Using correlation and regression analysis, the statistics shows that $\mathrm{PM}_{2.5}$ concentration has a positive relationship with temperature and a negative relationship with relative humidity and wind speed. As relative humidity and wind speed increases, $\mathrm{PM}_{2.5}$ decreases, while as temperature increases, PM2.5 also increases.
\end{abstract}

\section{INTRODUCTION}

\subsection{Background of Study}

As the Unmanned Aerial Vehicle (UAV) technology has gained popularity over the past years, this technology has been introduced for in-situ air monitoring (Peng, et.al, 2015). It addresses the different limitations imposed by the other methods including height and accuracy limitations, huge expenses, and limited data collection. Among Unmanned Aerial System (UAS), promising characteristics are long flight duration, improved mission safety, flight repeatability due to improving autopilots, and reduced operational costs when compared to manned aircrafts (Watts, Ambrosia, \& Hinkley, 2012). Knowing that UAVs are piloted not only horizontally but vertically as well, the emerging UAV with pollutant sensors is a new means of three-dimensional observation of air pollutants. It is an attempt of observing the horizontal and vertical distribution of particulate matter in atmospheric regions. Fixed air quality monitoring stations have several limitations when used to assess people's real life exposure to ultrafine particles and other traffic-related air pollutants, due to the large spatial variability of these pollutants in urban environments.

There are two types of drones in existence that can help in determining air quality. The first one is the fixed wing type that can carry larger payloads, but it must remain in an X-Y plane with constant motion. The second one is the multi-rotor UAV that can only carry small payloads, but has the capability of collecting samples while it is in motion and also when it is hovering over a specific location. Drones can be used successfully for this type of work because they are light in weight and can fly from one place to another relatively easily.
They are being used in various air quality control methods for measuring particulate matter and VOCs as well as measurements relating to meteorology such as temperature, humidity, pressure and winds (Medium, 2016).

During the World Environmental Health Day, last September 26, 2017, the Department of Environment and Natural Resources (DENR), together with the World Health Organization (WHO) Philippines highlighted the environmental risk of air pollution to the health of Filipinos. Urban areas are more exposed to dangerous levels of air pollution than those in rural (Miguel, 2017). Several groups including international organizations, such as the Asian Development Bank have supported initiatives to address Manila's serious air quality problems. There were studies to control vehicular emissions and improve the air quality in the city that led to the formation of the Metro Manila Air Quality Improvement Sector Development Program which ran from 1999 to 2002 (Krupnick, Morgenstern, Rolfe, Logarta, \& Rufo, 2003).

\subsection{Statement of the Problem}

In 2014, DENR stressed that the air quality in Metro Manila and other urban centers has reached internationally unacceptable levels that pose a "clear and present danger to human health strain" (Romualdez, 2014). Globally, over six million deaths are linked to indoor and outdoor pollution due to noncommunicable diseases (Miguel, C., 2017). Also, in 2002, a study conducted by the Department of Health show that the air people breathe in Metro Manila contains pollutants in excess of tolerable levels (Roces, 2002). In the Philippines, according to the WHO, about 1 in 4 deaths are attributed to air pollution. Carbon monoxide, lead, and nitrogen dioxide are only some of the pollutants floating in the air. 
Particulate matters which size is 2.5 microns/micrometers (PM2.5) and below penetrates to a person's lungs or cardiovascular system. From the standards from the WHO, the safe level for PM2.5 is 10 micrograms per cubic meter of air in a year. In Manila, the annual average of these pollutants is at $17 \mu \mathrm{g} / \mathrm{m} 3$ (Miguel, 2017). Based on the 2006 National Emission Inventory of DENR, $65 \%$ of air pollution comes from vehicles while $21 \%$ comes from stationary resources such as factories and burning of wastes. This year, 2017, Manila was named 10th Most Stressful City in the world wherein pollution levels is one of the factors considered. Metro Manila air quality is seriously degraded (Adel, 2017). Thus, there is really a need in the Philippines to strictly monitor the levels of pollutants especially in the cities, and implement the existing emission rules and guidelines more firmly because this problem is a national concern.

In 2009, the World Bank has an annual estimate of more than 1 million people who get sick and 15,000 die prematurely due to outdoor air pollution (OAP) in the Philippines. In addition to that, an annual estimate of 0.9 billion pesos for the cost of disease due to OAP while the annual income loss from mortality is more than 5.0 billion pesos. Aside from health problems, several international studies including the Philippines have also proven major agricultural productivity losses, causing a threat to food security (National Air Quality Status Report, 2015). Air quality is therefore of great national concern as it can affect the country's ecological balance and the health of every individual. This alarming environmental issue calls for an intensive monitoring of air quality in the Philippines to be able to generate necessary information in formulating a comprehensive air pollution management and control program.

In pursuant to RA 8749, the Department of Environment and Natural Resources (DENR), through the Environmental Management Bureau (EMB) regional offices compile emissions inventory every 3 years. These regional emissions inventory is then integrated to a national emissions inventory. This inventory covers emissions of the following pollutants - particulate matter (PM), sulfur oxides (SOx), oxides of nitrogen (NOx) and volatile organic compounds (VOC), carbon monoxide (CO) but due to limitation of resources, it is noted that not all regions are able to compile emissions to achieve $100 \%$ coverage of all of the sources (NAQSR, 2011).

From the above-mentioned pollutants, studies show that particulate matter (PM) has posed the biggest threat to human health as PM2.5 can penetrate deep into the lungs. It causes difficulty in breathing, lung tissue damage, and may aggravate existing cardiovascular diseases and lung problems cancercausing. Also, elderly and children are considered highly vulnerable to PM pollutant inhalation (NAQSR, 2015).

As stated in the National Air Quality Status Report for 2015, there are around 27 continuous monitoring stations in the Philippines measuring particulate matter (PM10 and PM2.5) and only four stations are allocated for measuring PM2.5 annual levels in the National Capital Region. The following table shows the annual levels of PM2.5 of four stations distributed in NCR for the year 2013 and 2014.

\begin{tabular}{|c|c|c|}
\hline Stations & $\mathbf{2 0 1 3}$ & $\mathbf{2 0 1 4}$ \\
\hline Commonwealth Ave. QC & - & 50 \\
\hline DLSU Taft, Manila & 21 & 19 \\
\hline DPWH, Timog EDSA, QC & 36 & 43 \\
\hline PLV, Valenzuela City & 29 & 29 \\
\hline
\end{tabular}

Table 1. $\mathrm{PM}_{2.5}$ annual levels in NCR monitoring stations

(Source: NAQSR, 2015)
Aside from the lack of monitoring stations, the data being reported is in annual level making it inadequate for people to assess the day to day or even month to month condition of ambient air pollution. Equipment breakdown and maintenance problems also contribute to the failure of meeting the required data capture rate for the emission inventory. The demand for fast, efficient, limitless, and continuous data collection for air quality monitoring emerges from this problem and the researchers supposed that this study would address the issue.

\subsection{Objectives}

This study aims to verify the technological feasibility of mobile sensors-carrying UAV as an effective and flexible means of measuring PM 2.5 concentration and vertical distribution. This study also aims to determine the vertical distribution of particulate matter using integrated $\mathrm{PM}_{2.5}$ sensor and UAV. With the data from the UAV and the said sensor, this research also aims to identify the relationship between the $\mathrm{PM}_{2.5}$ vertical distribution and the meteorological parameters namely temperature, relative humidity, pressure, wind speed, and altitude.

\subsection{Scope and Limitations}

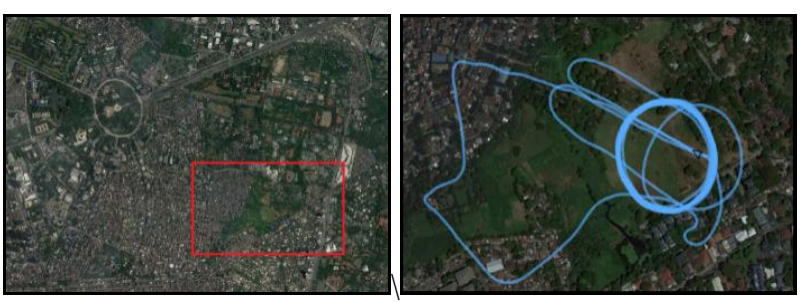

Figure 1. The project site: Hardin ng Rosas, an urban area in UP Diliman Campus of Quezon City, Metro Manila. (Flight path is represented by the blue lines) (Source: Google Earth Images)

This study was conducted to prove that UAV carrying mobile sensor as an effective tool to determine the $\mathrm{PM}_{2.5}$ concentration in a specific place at a specific time of the day and to determine its relationship to relative humidity, temperature, pressure, wind speed, and height. The factors being considered in this research are based from previous studies. These meteorological parameters were studied to have effects on the concentration of $\mathrm{PM}_{2.5}$.

The data acquisition was conducted in an urban area, Quezon City, specifically at Hardin ng Rosas in UP Diliman Campus (Figure 1). The researchers chose an open ground (Figure 2) within the study area that has no obstruction in order to perform the drone flight freely and undistracted, especially for take-off and landing. Also, the area satisfied the criteria that it should not be within the route of the airplanes used for public transport to avoid interference, and according to CAAP, the distance from the nearest airport should be more than $10 \mathrm{~km}$. In this case, Hardin ng Rosas is $21.7 \mathrm{~km}$ away from NAIA.

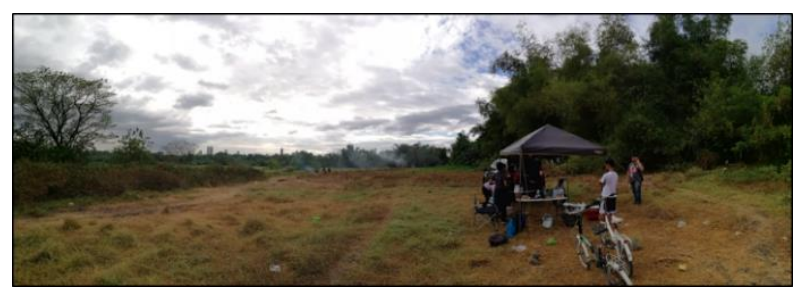

Figure 2. The project site: Open space 


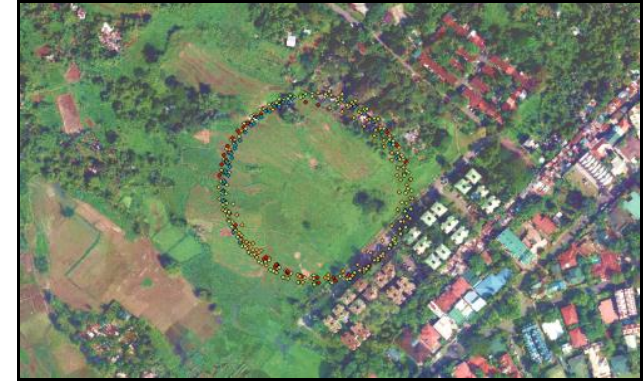

Figure 3. Experimental site: The area inside the circle which is approximately 2 hectares. (Source: UP Aerial Image)

The field experiment was conducted on March 22 covering a few flights only one flight was considered due to connection failure and data glitches on the other flights. This study discussed a flight from 4:50pm to 5:04pm. The flight covers only a portion of the study area with a radius of 80 meters as determined in the flight plan which is equal to an area of $20,106.19298 \mathrm{~m}^{2}$ or 2 approximately 2 hectares (Figure 3 ). The weather was sunny during the experiment and there were no chemical factories or other major polluting sources on the ground near the experimental site. It means that a vertical distribution of air pollutants in the experiments is not influenced by uneven distribution of major ground emission sources. Due to a limited number of flights, this research would not aim to learn the different patterns in different time periods under different meteorological conditions.

The pollutant sensor provides pollutant concentration for $\mathrm{PM}_{1}$, $\mathrm{PM}_{2.5}$, and $\mathrm{PM}_{10}$ but the study is limited only to estimating the $\mathrm{PM}_{2.5}$ concentration and determining its vertical distribution. This study was conducted to determine the relationship between $\mathrm{PM}_{2.5}$ concentration and meteorological parameters. The estimation of the pollutant was based on the regression models that were created. The relationship between the pollutant concentration and parameters were analyzed from those models.

\subsection{Research Significance}

Assessment of air quality has been traditionally conducted by ground-based monitoring, manned aircrafts and satellites. However, performing fast data collection at high altitudes is not always feasible due to the complexity of sites, moving sources, and physical barriers.

In the Philippines, air quality monitoring is being done by DENR Environmental Management Bureau (EMB). There are EMB regional monitoring stations that take measurements of criteria air pollutants in order to monitor the ambient air quality of the country. There are sampling equipments located all over the country classified according to the type of monitoring and criteria pollutants monitored in the existing National Air Quality Monitoring Set-up of DENR EMB. These air quality monitoring programs are General Ambient and Roadside Ambient. General air pollution monitoring stations are responsible for monitoring the ambient air quality of a fixed area, while, Roadside monitors near roads with large traffic volumes and assess air pollution caused by motor vehicles.

According to EMB, there are 27 monitoring systems for PMS $\left(\mathrm{PM}_{10}\right.$ and $\left.\mathrm{PM}_{2.5}\right)$ all over the country which are under continuous monitoring. In RA 8749, the National Ambient Air Quality Guideline Values for the parameters being measured by these stations are listed. However, for $\mathrm{PM}_{2.5}$, the guideline value has an averaging time of 24 hours and only four $\mathrm{PM}_{2.5}$ collectors are functional and usable. Also, these stations are stationary, thus, only the points within its signal can be recorded. From this lack of air quality monitoring stations in the Philippines, this study may help in providing supplementary tools to ground-based stations by addressing the different limitations including height and accuracy, huge expenses, and limited data collection.

This research intended to get $\mathrm{PM}_{2.5}$ concentration which is area and time specific. Using UAV with sensor, values of particulate matter can be obtained at a specific moment, may it be horizontally or vertically. This tool can be used for fast, efficient, limitless, and continuous data collection for air quality monitoring which may aid in health and transportation policymaking. Additionally, the UAV with mobile sensors can be used as in health-related studies such as determining the most polluted cities and tracing the source of pollutant emission during factory emission or even nuclear meltdown.

\section{REVIEW OF RELATED LITERATURE}

\subsection{Particulate Matter 2.5, its sources and Guideline Values}

Particulates or tiny particles of solid material or liquid aerosols can be present in the atmosphere and can be of pollution concern. Particle pollutants in the air can come from both natural and man-made sources such as smoke from forest fires and recreational sources, volcanic eruptions, vehicle exhaust emissions, industrial emissions, soil and road dust. Depending on the specific size, properties and environmental conditions, it may remain suspended in the air for a few seconds or indefinitely and travel from hundreds to thousands of kilometers (NAQSR, 2015).

$\mathrm{PM}_{2.5}$, which stands for Particulate Matter 2.5, is among the six common air pollutants according to the Clean Air Act EPA National Ambient Air Quality Standards. According to the The New York State Departments of Health (DOH) and Environmental Conservation (DEC), it is a fine particulate matter that is of biggest concern for people's health when level on air is high. Its size is 2.5 micrometers or less in width $(25$, 000 micrometers $=1$ inch). It affects health that it can travel deeply into the respiratory tract reaching the lungs.

Moreover, there are outdoor and indoor sources of these fine particles. Outside, fine particles primarily come from cars, buses, trucks, off-road vehicle (construction equipment, locomotive) exhausts, other operations that involve the burning of fuels such as wood, heating oil or coal and natural resources such as forest or grass fires. They can also be formed from the reaction of gases or droplets in the atmosphere from sources like power plants. These chemical reactions can occur miles from the original source of emissions. They can be carried long distances from their source, thus, events such as volcanic eruptions can raise fine particle concentrations hundreds of miles from the event (Health.ny.gov, 2018).

The Department of Environment and Natural Resources (DENR) took an important step to protect the health of Filipinos from particle pollution by setting the air quality standard for $\mathrm{PM}_{2.5}$. DENR Secretary Ramon J.P. Paje recently issued Department Administrative Order (DAO) No. 2013-13 setting the National Ambient Air Quality Guideline Value (NAAQGV) for PM2.5 at 75 micrograms per normal cubic meter $(\mu \mathrm{g} / \mathrm{Ncm})$ for an average of 24 hours or short term, and $35 \mu \mathrm{g} / \mathrm{Ncm}$ for an average of one year or long term, starting from the DAO's effectivity until Dec. 31, 2015. The DAO also provides tougher 
standards after 2015. Effective Jan. 1, 2016, the NAAQGV for the short and long terms will be at 50 and $25 \mu \mathrm{g} / \mathrm{Ncm}$, respectively (Miguel, 2013). A microgram is a unit of weight. There are a million micrograms in a gram, and a pound is equal to about 450 grams.

From all the discussed effects of air pollutants, this makes air quality of great concern as it can affect not only the health of every individual but the country's ecological balance and as well. This alarming environmental issue raises the need for an intensive monitoring of air quality in the country to help in formulating a comprehensive air pollution management and control program and even for health policy making. These threats being posed by $\mathrm{PM}_{2.5}$ pollutant to public health and its domino effects became the motivation of the researchers to come up with a study that would help in monitoring this harmful pollutant.

\subsection{Unmanned Aerial Vehicles for Air Quality Measurements}

Assessment of air quality has been traditionally conducted by ground bases monitoring and more recent, by manned aircrafts and satellites. To quantify the effects of atmospheric pollution on human health and environment, detailed information on the characteristics of aerosol distribution and pollutant concentration is needed (Peng, et. al., 2015). However, data from ground bases and satellite measurements are relatively low and often inadequate. Additionally, satellite and sensors can be costly resulting to restrictions in the analysis. These limitations together suggest the use of small, lightweight UAVs for atmospheric measurements and monitoring.

These small, lightweight UAVs can provide more accurate information on aerosol or air pollutant vertical distribution throughout the atmospheric column, which is needed to understand air quality and composition in specific atmospheric layers (Villa et. al., 2016 and Peng, et. al., 2015). Historically, various approaches were used for vertical measurements of aerosol but their limitations give rise to the application of UAVs in atmosphere measurements:

- Meteorological tower is used for measuring the vertical distribution of air pollutants. Because of a limited height and lack of flexibility, meteorological tower is able to measure air pollutants at near-ground height but misses those in the middle- and high-level of planetary boundary layer (Peng, et. al., 2015).

- The emergence of mountain measurements has overcome the shortcomings of meteorological tower. However, mountain measurements are usually conducted at some specific altitude and cannot describe the concentration gradient of air pollutants with the increase of vertical height (Peng, et. al., 2015).

- Recently, satellite-based remote sensing effectively observes temporal and spatial variation of tropospheric air pollution at multi-scales, but it just integrates the entire column from the surface to the top of the atmosphere as a single layer without vertical gradient measurement. This is an improvement in acquisition but the measurement accuracy is limited due to lack of sufficient data validation (Peng, et. al., 2015).

- Sometimes, piloted aircrafts and tethered balloons are directly used to collect continuous data at various altitudes of the atmosphere. Due to the huge expenses of piloted aircrafts and tethered balloons, these methods are seldom used in research experiments (Peng, et. al., 2015).

With this revolutionary new method to monitor ambient air pollutant, UAVs could cover large areas and could monitor remote, dangerous, or difficult to access locations, increasing operational flexibility and resolution over land-based methods (Villa et. al., 2016). The capacity of UAVs to ascend vertically is important in studying the vertical distribution of air pollutants which can further uncover the exchange of mechanism in the atmosphere between atmospheric layers, as well as the interaction of internal and external air pollutants (Peng et al., 2015). The advantages of unmanned aerial vehicle over any other type of platforms such as accuracy, flexibility, limitless height exploration, and continuous data collection, was the basis for selecting this instrument for this study.

\subsection{Vertical Distribution Patterns of $\mathbf{P M}_{2.5}$ using UAV}

A study from Shanghai Jiao Tong University of Shanghai, China demonstrated the feasibility of UAV equipped with mobile monitoring devices as an effective and flexible means to collect three-dimensional air pollutant concentration data, particularly for monitoring the vertical profile of air pollutants. The objective was to collect three-dimensional fine particulate matter $\left(\mathrm{PM}_{2.5}\right)$ mass concentration data on sixteen flights within $1000 \mathrm{~m}$ altitude covering the months of August to December 2014 in Hangzhou, China. It was also an attempt to identify the spatial patterns of $\mathrm{PM}_{2.5}$ concentrations at three-dimensional scale and to understand the reasons of vertical distribution patterns (Peng et al., 2015).

The project area was situated in Lin'an, a city of Hangzhou, China covering a $4 \mathrm{~km}$ by $4 \mathrm{~km}$ area for collecting data at 300 to $1000 \mathrm{~m}$ height. A lightweight fixed-wing UAV was used to fly autonomously following the design flight path in an auto-pilot system. To collect for $\mathrm{PM}_{2.5}$ and meteorological data, a suite of mobile sensors were attached to the UAV:

- Sidepak AM510 PM Detector was used for getting the mass $\mathrm{PM}_{2.5}$ concentration. It records the concentration data every two seconds with a minimum resolution of 1 $\mathrm{mg} / \mathrm{m} 3$. Air is pumped into a sampling tube through an inlet that towards the UAV tail in order to avoid the effect of variation of the flow rate.

- Temperature and relative humidity were recorded by HOBO U12 Temp/RH Data Logger. It records temperature with a resolution of 0.03 degree Celsius and records relative humidity with a resolution of $0.03 \%$ every two seconds.

- Columbus V-900 Multifunction GPS Data Logger logs the 3D location data of the UAV every second.

From this study, the researchers adopted the methodology of integrating the UAV with the mobile sensors. The flight design such as the ascending of the UAV with the gradual increase in height was taken on as well, but with alteration on the flight plan, maximum flight height, and others with the consideration on the limitation of resources. Factors considered in this research such as the temperature, relative humidity, pressure, altitude are adopted as well with the addition of wind speed and wind direction.

The treatment of data and statistical analysis including Pearson correlation and multiple regression analysis used in this study was integrated into the methodology of the research. The methods on the visualization of outputs such as three- 
dimensional graphs of concentration and vertical profiles of meteorological parameters were as well used for this research.

\subsection{Challenges in using UAV}

This emerging unmanned aircraft technology faces challenges that somehow slow down the development. The increase in drone use which recently gains popularity raises privacy concerns and even the word "drone" has a real negative first impression. It is noted that for a technology be accepted as a research tool, showing the benefit is essential. Moreover, there are restrictions that are being imposed for the usage of UAVs. Aviation interference is a primary concern. Safety and protection of property are driving additional challenges. Different countries have imposed rules and regulations for UAVs that govern the use of small UAVs and legally limit the commercial use unless permits are obtained.

On the technical side, UAVs' sensitivity of components can create flight issues which effects need to be minimized. UAV electronics may interfere with some instruments like vibration effects can impact some instruments. Nonetheless, new generation lightweight UAVs and sensors were being used for meteorological, particulate matter, continuous gas measurements and integrated gaseous sampling of course under certain regulations (Baxter and Bush, 2014).

Given these challenges discussed and with the current rules and regulations for the usage of UAV in the Philippines, there are several factors that must be considered for the conduct of the research. If possible, there must be consultation and formal permission from appropriate authority to be able to have a successful experiment and for the completion the research's objectives.

\section{METHODOLOGY}

\subsection{General Methodology}

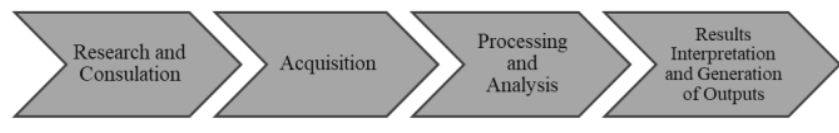

Figure 4. General Methodology

There are four parts in the general methodology of this study as seen in Figure 3.1. The first part is on the Research and Consultation which is for the formulation of methodology, specification for the UAV flight plan and design, factors to consider, and methods on the analysis of data. Next is the Acquisition which is divided into Instrument Integration, customizing of the platform to be used, and Data Acquisition which includes the test flight and actual data gathering. The third part is on the Processing and Analysis which subdivided into two. The Data Pre-Processing for the matching and syncing of UAV and sensor data and checking for corrupted data then the Statistical Analysis for the determination of the relationship between the observed parameters and evaluation of results. The last part is on the Results Interpretation and Generation of Output for creating of three-dimensional distribution graphs of meteorological parameters and $\mathrm{PM}_{2.5}$ concentration, vertical profiles of the parameters, and visualization of the estimation of concentration.

\subsection{Research and Consultation}

Previous studies were used to formulate the applicable steps for this study. Some of the specifications needed for the flight or data acquisition were adopted from a methodology of a previous study. This includes a gradual increase in height during flight plan, manual mode for takeoff and landing, autonomous mode when it arrives a certain height and the idea of dividing the flight into of height intervals for analysis. Despite having these specifications adapted from the study, there were certain adjustments done to cope with the resources available. Maximum height was changed to $500 \mathrm{~m}$ instead of $1000 \mathrm{~m}$ and starting height of autonomous mode was set to $80 \mathrm{~m}$ and not $300 \mathrm{~m}$ as used in the literature. This is due to the limitation imposed by the UAV used and the limited resources. Cylindrical path with a gradual increase in height per second was used and not a rectangular path as used in the literature to be able to optimize the data gathering and have well distributed data points.

Also, factors that were considered in this study were adapted from the literature reviewed such as the temperature, relative humidity, pressure, altitude. This research further analyzes the behavior of $\mathrm{PM}_{2.5}$ concentration with the addition of two other factors which are the wind speed and wind direction that were not considered in the literature reviewed. Since the methodology will involve UAV survey, the researchers consulted with Sir Patrick Ostrea of EissenPatt, a licensed pilot, to be able to verify the flight details and specifications for the UAV survey.

The bottle neck of this study was acquiring the air quality sensor to be integrated with the UAV. With the help of one of the thesis advisers, Engr. Ramos, the researchers acquired the PM sensor from project CrowdSSense of the Institute of Chemistry, UP Diliman under the supervision of Dr. Rheo Lamorena of Institute of Chemistry and Dr. Mark Talampas of the Institute of EEE, UP Diliman. Our direct consultant for matters regarding the sensor was Sir Paul Alexander Darvin, a research associate from the project. The PM sensor acquired can measure temperature, relative humidity, $\mathrm{PM}_{1}, \mathrm{PM}_{2.5}$, and $\mathrm{PM}_{10}$ which provides us the needed data for this study, the meteorological parameters (temperature, relative humidity) and $\mathrm{PM}_{2.5}$.

For the treatment of data and methods on the statistical analysis, the researchers have consulted Sir Ruzzel Ragas of the UP Diliman School of Statistics. He verified the steps on the statistical methods that were adopted from the literature as well as the results of the statistical analysis.

\subsection{Acquisition}

\subsubsection{Instrument Integration}

As discussed, the air quality sensor was acquired from CrowdSSense under the collaboration of the Institute of Chemistry and the Electrical and Electronics Engineering Institute, UP Diliman.

This $10 \times 4.5 \times 4 \mathrm{~cm}$ unit weighs 170 grams (Figure 3.2). It has an LED display showing the measurements of $\mathrm{PM}_{1}, \mathrm{PM}_{2.5}$, and $\mathrm{PM}_{10}$ concentrations, temperature, and relative humidity readings, and the battery level. It is composed of two kinds of sensing elements: 1) Temperature and Relative Humidity Sensor, 2) Particulate Matter Sensor. This unit is being used by the project to record PM concentrations together with other parameters while walking, jogging, or cycling around an urban area. 

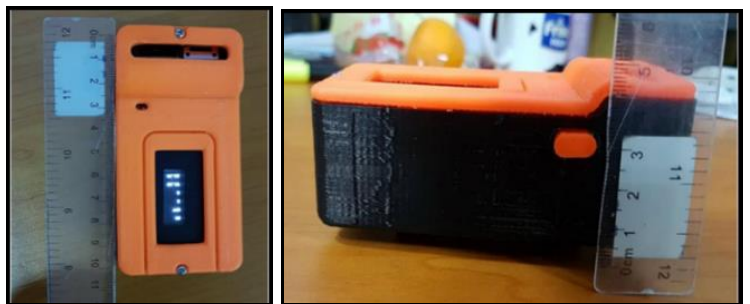

Figure 5. Air quality sensor acquired from CrowdsSense

The PM mass concentration sensing element is PMSA003 manufactured by Plantower (Figure 3.3). PMSA003 is a type of digital and universal particle concentration sensor. It measures $38 \times 35 \times 12 \mathrm{~mm}$ and can distinguish up to 0.3 micrometerdiameter of a particle. It can be used to obtain the number of suspended particles in the air. After measuring the concentration of particles, it will output them in the form of digital interface. This sensor can be inserted into a variety of instruments related to the concentration of suspended particles in the air or other environmental improvement equipments to provide correct concentration data in time.

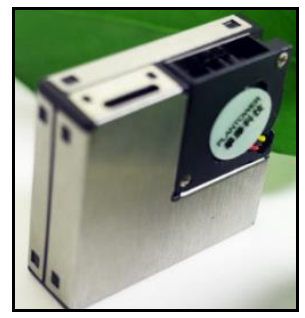

Figure 6. Air quality sensor (Model: PPMSA003 by Plantower, Image Source: Plantower)

The PM sensor works by Laser scattering principle. When light strikes suspended particles in the air, the light scatters. For certain particle properties, the intensity of the light scattered off the particle is proportional to its mass concentration. By determining the intensity of the scattered light, the particle mass concentration can be obtained by applying the conversion coefficient. Light passes through the particle matter under certain conditions based on the number of particles and the particle size approximately equal to the wavelength of the light.

The exact solution for the scattering of a pair of particles can be obtained after dust concentration detection by strict mathematical deduction via Maxwell's equations. In the sensor, the measuring of particle diameter, number of particles with different diameter per unit volume, and determining the mass concentration is being calculated by a microprocessor.

Temperature and relative humidity were recorded by HTU21DF RHT sensing module from Adafruit every second. The temperature is being recorded with an accuracy of $\pm 1^{\circ} \mathrm{C}$ from 30 to $90^{\circ} \mathrm{C}$, while in humidity, the accuracy is $\pm 2 \%$ from $5 \%$ to $95 \%$.

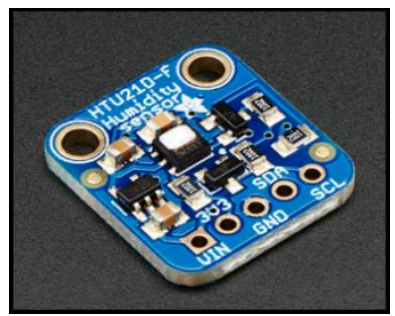

Figure 7. Humidity and Temperature Sensor (Model: HTU21DF by Adafruit)
The PM sensor records the concentration data every one second with a resolution of $1 \mathrm{ug} / \mathrm{m} 3$. In this unit of two sensors, to obtain the PM concentrations together with other parameters, there is an Android application that needs to be installed in a mobile phone to set-up the data logger. The sensor and mobile phone will be connected via Bluetooth. To be able to record the data, the phone will first scan the mobile sensor then the data logger needs to be activated and saved The output file is in comma separated values file or CSV file.

The UAV used in this research is customized by Eisenpatt Solutions through Mr. Patrick Ostrea. It was aligned with the site condition wherein there is a short take-off and landing, thus it should have the ability to fly at low speed. The weight of the payload is also considered. For the vehicle type, a lightweight fixed-wing UAV was used in this experiment that can carry up to $2 \mathrm{~kg}$ payload. The wing-span of the aircraft is about 1.50 meters. The UAV can fly autonomously following the flight path designed in advance by the auto pilot system, while it should be launched and recovered by a human pilot.
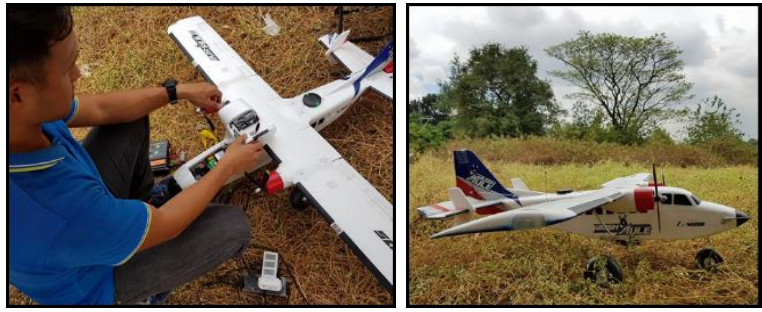

Figure 8. Lightweight fixed-wing UAV owned by Sir Patrick Ostrea (Photos taken during fieldwork)

In this study, the XY coordinates and elevation of each data point were derived from the UAV GPS data logger. Pressure from attached barometer and wind speed from sensing module were also extracted from the UAV. The flight path and plan were designed using ArduPilot, an open source unmanned vehicle Autopilot Software Suite, from which UAV data were recorded.

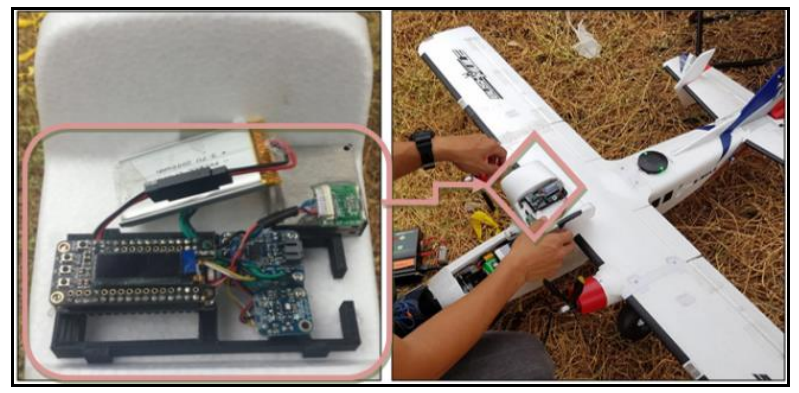

Figure 9. Integrated Air Quality Sensor and lightweight fixedwing UAV (Photos taken during fieldwork)

Since the UAV can only lift up to $2 \mathrm{~kg}$ load, the sensor's housing case was removed in order to lessen its weight. The sensors were mounted on top of the fuselage hatch or "pilot area" of the fixed-wing UAV, which is near the nose of the aircraft so that the laminar flow of air is consistent with the air speed and not influenced by the turbulence of propellers. Builtin battery of the CrowdsSense sensor was detached and the UAV was used as a life-support of the sensor. It was attached to the UAV's 16V (98 W-h) battery. 


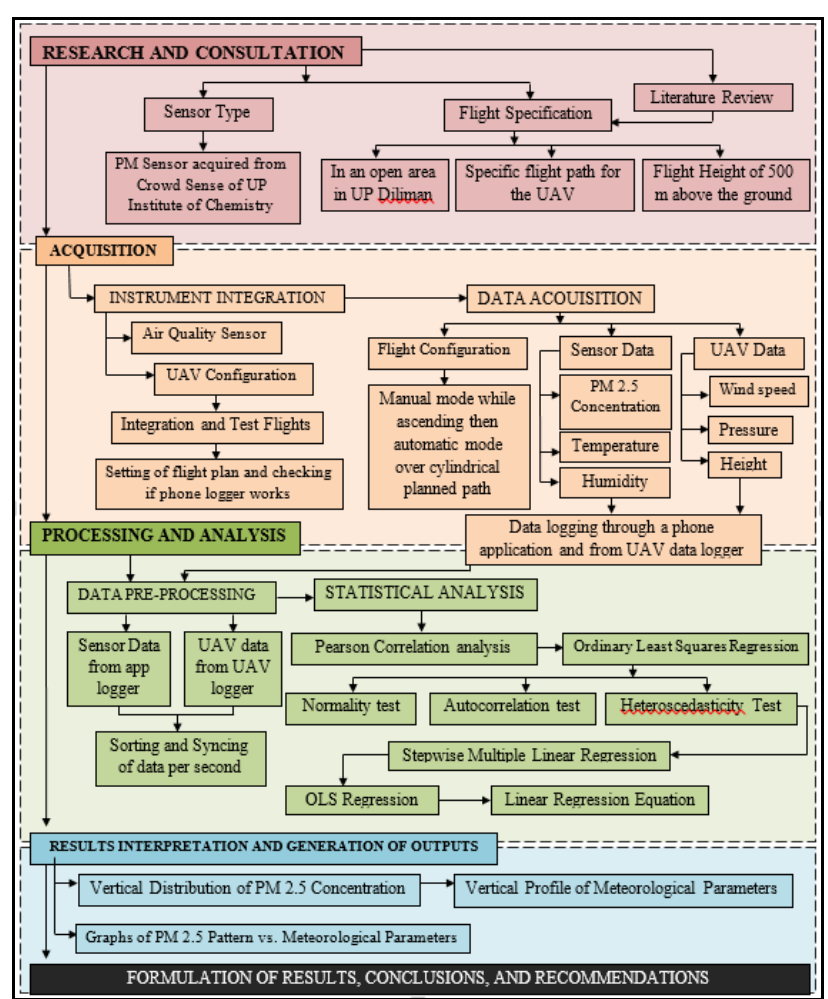

Figure 10. Research framework and detailed methodology

For the recording of air quality sensor data, a phone was placed and taped under the top fuselage hatch and was connected via Bluetooth to the sensor. The flight plan was plotted using ArduPilot and test flights were held to check if the phone logger application works.

\subsubsection{Data Acquisition}

The data acquisition was conducted in an urban area, Quezon City, specifically at Hardin ng Rosas in UP Diliman Campus. ArduPilot was used for the designing the flight plan. During the data acquisition, this displays the measured parameters and of the UAV during flight. The UAV was launched by a licensed pilot and was switched to autonomous mode after arriving at 80 meters. The considered flight in this paper lasted for 14 minutes \& 41 seconds.

The PM sensor data was recorded in $\mu \mathrm{g} / \mathrm{m}^{3}$. Relative humidity and temperature were acquired from the sensor. Pressure, wind speed, and height were derived from the UAV. Data logging was done through a phone application that uses Bluetooth to connect to the sensor. The concentration of the said particulate matter at different heights per second was recorded. For the position of the UAV, the position coordinates and elevation of each data point were derived from the UAV GPS data logger.

For the flight configuration, the UAV was launched by a licensed pilot, and then was switched to autonomous mode when it arrived at 80 meters. It continued traversing the planned path, a cylindrical-path type, in autonomous mode. The planned path was a cylindrical-path type to fully optimize the data gathering and to have well distributed data points. The UAV was parallel to the surface that gained altitude gradually. It descended back to the ground after reaching maximum altitude that was set to 500 meters. Maximum height was set to $500 \mathrm{~m}$ due to the limitation of the battery. One whole flight make used of $60 \%$ of the UAV. The flight considered in this paper lasted for 14 minutes and 41 seconds from the time it took off up to the time it landed.

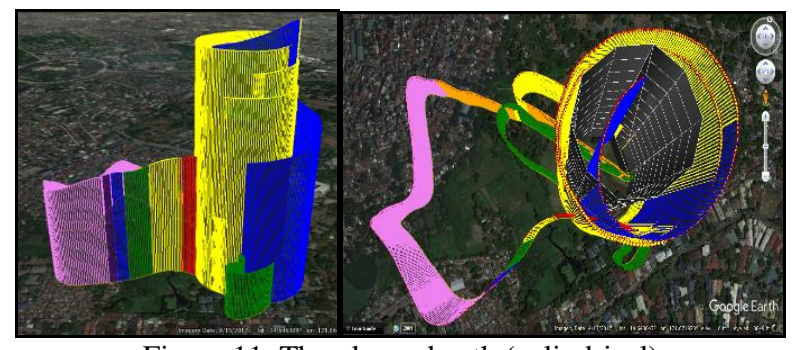

Figure 11. The planned path (cylindrical)

\subsection{Processing and Analysis}

\subsubsection{Data Pre-processing}

The PM sensor which was integrated to the UAV measured the concentration of particulate matter 1, 2.5, 10 and meteorological parameters (temperature, relative humidity, pressure, wind speed) at different heights per second. It was recorded in the phone placed in the UAV from which it was downloaded and sorted. The position coordinates and elevation of each data point were recorded per second in the UAV GPS data logger. It was processed and extracted using ArduPilot.

The sensor data $\left(\mathrm{PM}_{1}, \mathrm{PM}_{2.5}, \mathrm{PM}_{10}\right.$, temperature and relative humidity) and UAV data (position coordinates, elevation data, pressure, and wind speed) were synced and matched using the time stamp of each data point. The resulting csv file contains the PM concentrations, temperature and relative humidity readings, pressure, wind speed, XY-coordinate, and height of each data point. Data points for takeoff and descending were removed, only the points over the cylindrical path were included in the analysis. During the flight, Bluetooth connection became a problem resulting to glitches in the data, like high points, corrupted values and outliers. These were removed in the data set as well.

\subsubsection{Statistical Analysis}

To identify the relationship between the $\mathrm{PM}_{2.5}$ vertical distribution and the meteorological conditions, statistical analysis was applied to the data acquired which includes Correlation and regression analysis.

\subsubsection{Pearson Correlation Analysis}

The researchers used the correlation coefficient to analyze the effects of meteorological parameters to $\mathrm{PM}_{2.5}$ concentration since Pearson correlation coefficient can reflect the linear correlation between two variables. The strength of correlation between the independent variables and dependent variables can be determined through this analysis. The independent variables were the temperature, relative humidity, pressure, wind speed and height while $\mathrm{PM}_{2.5}$ concentration at different altitude as the dependent variable.

\begin{tabular}{|c|c|}
\hline Independent Variable & Dependent Variable \\
\hline Temperature & $\mathrm{PM}_{2.5}$ Concentration \\
\hline Relative Humidity & \\
\hline Pressure & \\
\hline Wind speed & \\
\hline Height & \\
\hline
\end{tabular}

Table 2. Dependent and Independent Variables 


\subsubsection{2}

\section{Ordinary Least Squares}

Ordinary Least Squares regression (OLS) is more commonly named linear regression.

In the case of a model with $\mathrm{p}$ explanatory variables, the OLS regression model writes:

$$
\mathrm{Y}=\beta_{\mathrm{o}}+\sum_{\mathrm{j}=\mathbb{1}_{\mathrm{m}} \mathrm{p}} \beta_{\mathrm{j}} \mathrm{X}_{\mathrm{j}}+\varepsilon
$$

$$
\begin{aligned}
& \text { where } \quad \begin{array}{l}
Y=\text { dependent variable } \\
\beta_{0}=\text { intercept of the model } \\
X_{\mathcal{J}^{-}}=\text {jth explanatory variable of the model }(j=1 \text { to } p) \\
\varepsilon=\text { random error with the expectation } 0
\end{array}
\end{aligned}
$$

A regression equation is a measure of the extent to which the researchers can predict one variable from another. It will explain how the dependent variable acts when one of the independent variables is changed.

\subsubsection{Checking Assumptions of Linear Regression}

\section{Shapiro-Wilk Test for Normality}

Normality test is for the normal distribution requirement of a regression model. The dependent variable should satisfy this. In order to test for normality of the dependent variables, we test the distribution of variables' residual error. It should be drawn from the histogram that the residual error $\varepsilon$ is fitted to the normal distribution. The variables' residual errors should show a linear characteristic.

The Shapiro-Wilk test for normality is one of three general normality tests designed to detect all departures from normality. The test rejects the hypothesis of normality when the p-value is less than or equal to 0.05 . Failing the normality test allows you to state with $95 \%$ confidence the data does not fit the normal distribution. Passing the normality test only allows you to state no significant departure from normality was found.

\section{Breusch - Pagan Test for Heteroscedasticity}

It tests whether the variance of the errors from a regression is dependent on the values of the independent variables. Ordinary least squares constrain these so that their mean is 0 and so, given the assumption that their variance does not depend on the independent variables, an estimate of this variance can be obtained from the average of the squared values of the residuals.

Heteroscedasticity refers to the circumstance in which the variability of a variable is unequal across the range of values of a second variable that predicts it.

\section{Durbin-Watson Test for Autocorrelation}

The normality test and correlation analysis are conditions that should be met before proceeding to the multiple regression. Also, before using the multiple linear regression method to model the vertical distribution of $\mathrm{PM}_{2.5}$, we need to take the autocorrelation of the parameters since the observed data is closely related with time. The autocorrelation in the dataset was tested with Durbin-Watson test.

In this research, autocorrelation measures the relationship between a variable's current value and its past values. Autocorrelation measures linear relationships; even if the autocorrelation is miniscule, there may still be a nonlinear relationship between a time series and a lagged version of itself.

For the test that was used, Durbin-Watson, is a test that detects the presence of autocorrelation. Durbin-Watson values or DW values always lies between 0 and 4 . If the Durbin-Watson statistic is substantially less than 2, there is evidence of positive serial correlation. As a rough rule of thumb, if Durbin-Watson is less than 1.0, there may be cause for alarm. Positive serial correlation is a serial correlation in which a positive error for one observation increases the chances of a positive error for another observation. On the other hand, negative serial correlation implies that a positive error for one observation increases the chance of a negative error for another observation and a negative error for one observation increases the chances of a positive error for another.

\subsubsection{Step-wise Regression}

At each step, the variable is being evaluated to see if it should remain in the model. The actual set of predictor variables used in the final regression model must be determined by analysis of the data. Determining this subset is called the variable selection problem. Finding this subset of regressor (independent) variables involves two opposing objectives. First, we want the regression model to be as complete and realistic as possible. We want every regressor that is even remotely related to the dependent variable to be included. Second, we want to include as few variables as possible because each irrelevant regressor decreases the precision of the estimated coefficients and predicted values. Also, the presence of extra variables increases the complexity of data collection and model maintenance. The goal of variable selection becomes one of parsimony: achieve a balance between simplicity (as few regressors as possible) and fit (as many regressors as needed).

Stepwise regression is a modification of the forward selection so that after each step in which a variable was added, all candidate variables in the model are checked to see if their significance has been reduced below the specified tolerance level. If a non-significant variable is found, it is removed from the model.

\subsubsection{Linear Regression Model}

After determining the significant variables affecting the $\mathrm{PM}_{2.5}$ concentration distribution and the insignificant variables using the stepwise linear regression, the insignificant variable needs to be removed from the list of independent variables to have a better multiple regression model for the vertical distribution of $\mathrm{PM}_{2.5}$. Ordinary Least Squares Regression will then be executed in order to determine the final and most acceptable regression model. This model would serve as the estimation of $\mathrm{PM}_{2.5}$ concentration vertical distribution at different heights with varying meteorological conditions. The result of this analysis would be a linear regression equation with determined coefficients of variables.

\subsection{Results Interpretation and Generation of Output}

The results of the statistical analysis implemented in this research are interpreted to be able to determine the relationship between the PM2.5 concentrations and the meteorological parameters. From the regression equation, the most significant or most influential factors were determined. Their effects on the pollutant concentration were also noted and interpreted from the 
correlation coefficients and from their coefficients in the equations.

To be able to visualize the vertical distribution of PM2.5 concentration, three dimensional graphs were created. Also, for the visualization of the PM2.5 concentration behavior with respect to the independent variables, graphs showing the relationship between the pollutant and the meteorological parameters were created (PM2.5 concentration versus relative humidity, temperature, pressure, and height).Vertical profiles of meteorological parameters (relative humidity, temperature, pressure, wind speed, and height) were created to visualize the behavior of the factors during the flight.

\section{RESULTS AND DISCUSSION}

\subsection{Data Integration}

\subsubsection{Three- dimensional Distribution of $\mathbf{P M}_{2.5}$ Concentration}

The three-dimensional distribution or vertical distribution of $\mathrm{PM}_{2.5}$ concentration is shown in figure 4.1. The experiment shows that generally the $\mathrm{PM}_{2.5}$ concentration decreases as the height increases. As for the horizontal distribution or the near ground data (less than 80 meters), there is an evident fluctuation of $\mathrm{PM}_{2.5}$ concentrations which is a result of the accumulated pollutant emission of human activities during in situ and the varied meteorological conditions. It was removed from the data to avoid its random effect on the analysis. Also, the UAV started flying over the cylindrical path at 80 meters and it was set on automatic mode while gradually increasing its height. The UAV completes a cycle every 40 meters which will be named as flight cycle in this analysis.

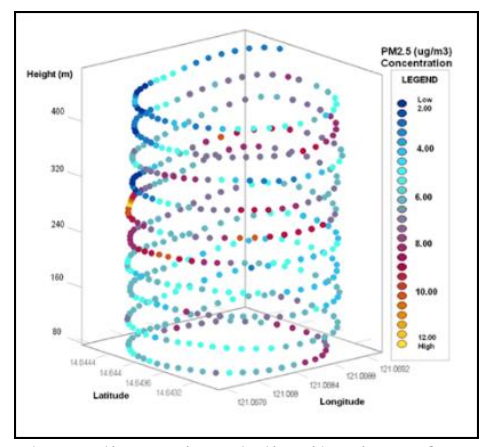

Figure 11. Three-dimensional distribution of PM2.5 (\%) on March $22^{\text {nd }}$

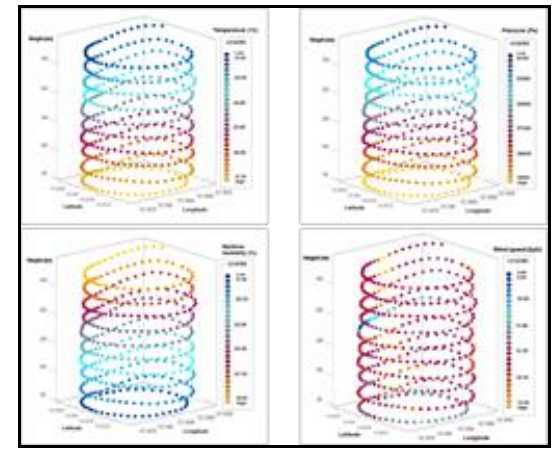

Figure 12. Three-dimensional distribution of Independent Variables

Temperature (upper left), Pressure (upper right), Relative humidity (lower left), Wind speed (lower right)
Three-dimensional distributions of the meteorological parameters (Figure 12) show the relationship between the parameters to the $\mathrm{PM}_{2.5}$ concentration. Temperature and pressure are generally decreasing with the increase in altitude while relative humidity is increasing with the increase in altitude. For the wind speed, the values were varying as altitude increase but it is observable that sudden change of wind speed happened in height 240 to 300 meters.

Figure 13 shows the boxplot of the $\mathrm{PM}_{2.5}$ concentrations at each height interval during the flight without the near ground concentration which is less than 80 meters. Generally, the $\mathrm{PM}_{2.5}$ concentration decreases as the height increases with an exception in the height interval 200 to 280 meters. It can be observed that during the flight, a sudden change of atmospheric conditions at the height of 200 to 280 meters causing the rising of $\mathrm{PM}_{2.5}$ concentration then slowly decreasing above 280 meters.

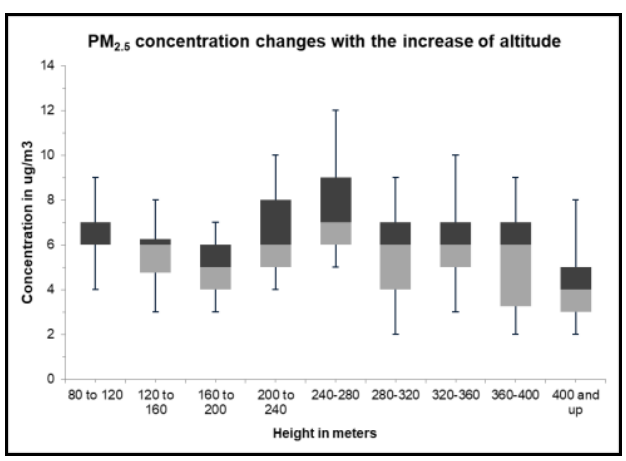

Figure 13. Boxplot of $\mathrm{PM}_{2.5}$ concentration changes with the increase of altitude on March 22nd.

\subsubsection{The relationship between meterological condition of PM2.5 concentrations}

It can be observed that the $\mathrm{PM}_{2.5}$ concentration measured during the whole flight was less than $12 \mu \mathrm{g} / \mathrm{m}^{3}$. The relative low concentration of $\mathrm{PM}_{2.5}$ can be explained by the weakening of solar radiation in the afternoon. The temperature of the atmosphere continues to rise and the local temperature difference and airflow increase. This may also be caused by the increase in the stability of the atmosphere in the late morning where rapid vertical transport of particle matters may occur resulting in sudden escape and fast movement of particulate matter. This contributes to the mixing of pollutant in the altitude. As a result, the vertical gradient of the $\mathrm{PM}_{2.5}$ concentration decrease causing the registration of low particle count. Figure 3 shows the average $\mathrm{PM}_{2.5}$ concentration per height interval; note that the height interval was based on the flight cycle of the UAV which is 40 meters.

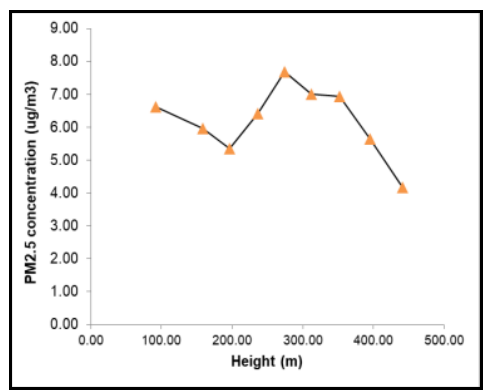

Figure 14. $\mathrm{PM}_{2.5}$ concentration changes with the increase of altitude 


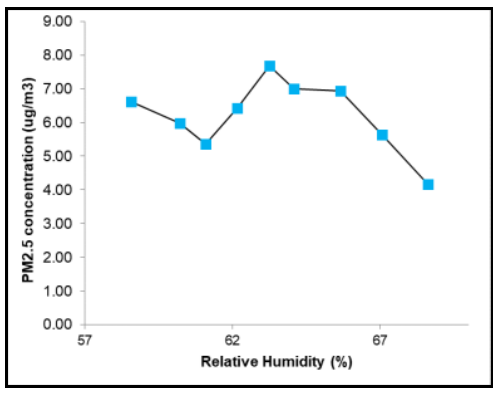

Figure 15. $\mathrm{PM}_{2.5}$ concentration changes with the increase of relative humidity $(\%)$

As shown in figures 14 and 15 , the behavior of $\mathrm{PM}_{2.5}$ concentration as it changes with respect to height and relative humidity are identical which means that these two factors may have the same effect on the pollutant. On the other hand, the increase in temperature and increase in pressure have the same effect on the $\mathrm{PM}_{2.5}$ concentration behavior as shown in figures 16 and 17. The same trends can be observed for the two meteorological factors when plotted with $\mathrm{PM}_{2.5}$ concentration.

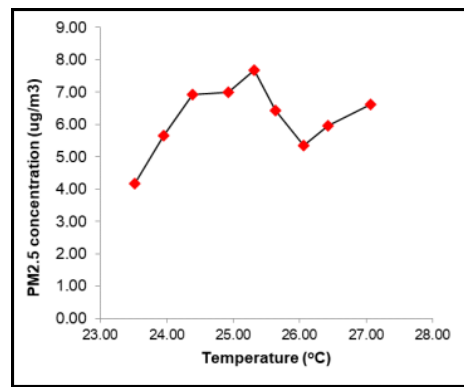

Figure 16. $\mathrm{PM}_{2.5}$ concentration changes with the increase of temperature

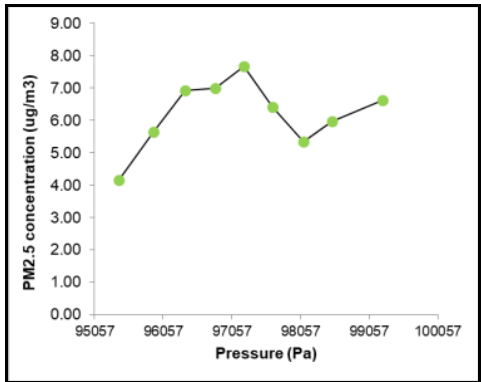

Figure 17. $\mathrm{PM}_{2.5}$ concentration changes with the increase of pressure

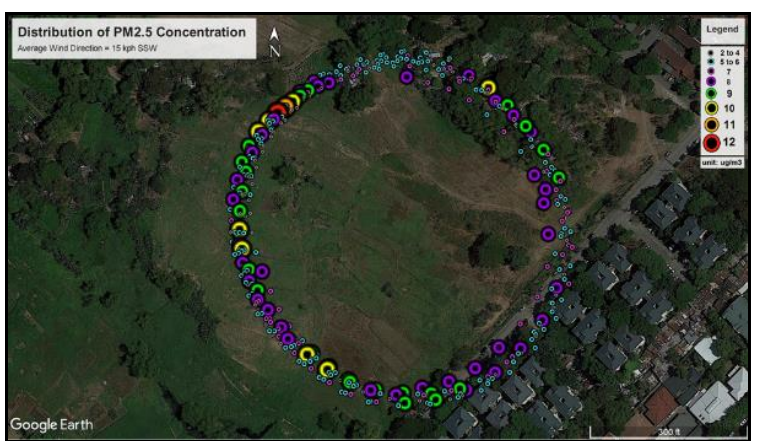

Figure 18. Horizontal Distribution of $\mathrm{PM}_{2.5}$ Concentration in the study area

From the figure above, we can observe that high concentration of $\mathrm{PM}_{25}$ is dominant in the western part of the area. This may be explained by the wind direction during the flight which was 15 kph south-west transporting pollutant particles to the western side of the area. Another explanation would be the setting of the project site. There is a highly urbanized area in the western side of the site (see Figure 18) which would be the immediate source of pollutant.

\subsection{Statistical Analysis}

\subsubsection{Pearson Correlation Analysis}

The effects of meteorological condition's on dilution, diffusion, and accumulation of pollutants have been commonly recognized in the previous studies reviewed in this research. The researchers first use the correlation coefficient to analyze the relationship since Pearson correlation coefficient can reflect the linear correlation between two variables. The strength of correlation between the independent variables and dependent variables can be determined by Pearson correlation analysis. In this study, the temperature, relative humidity, pressure, wind speed and height were selected as the independent variables and PM2.5 concentration at a different altitude above ground as the dependent variable.

From previous researches, the wind direction is noted to be an important variable that affects PM2.5 concentration distribution but because of the unavailability of wind direction instrument, it is not considered in this analysis. Even if the instruments are put on the UAV, the turbulence caused by the movement of UAV would result in difficulties in measuring the actual wind direction. Actually, the wind speed recorded in this experiment was average values only considering the wobbling of the UAV and other factors. This is indeed the limitation of this analysis.

The Pearson correlation coefficients among the observed parameters are calculated and the results are shown in Table 3. Pearson correlation analysis shows that independent variables temperature, relative humidity, pressure, wind speed, and height have a low correlation with the respect to the PM2.5 concentration. Among the independent variables, relative humidity has the highest correlation with PM2.5 concentration with the correlation coefficient of -0.2736 . Observe that relatively humidity, wind speed, and height stay negatively correlated with the dependent variable. It is also noted that variables temperature and pressure are positively correlated negatively correlated with the dependent variables. Among the independent variables, pressure is the least correlated with the pollutant.

\begin{tabular}{|c|c|c|c|c|c|}
\hline & Temp & $\begin{array}{c}\text { Relative } \\
\text { Humidity }\end{array}$ & Pressure & Height & $\begin{array}{l}\text { Wind } \\
\text { Speed }\end{array}$ \\
\hline & 0.260 & $\mathbf{- 0 . 2 7 3 6}$ & 0.1310 & -0.2289 & -0.2683 \\
\hline
\end{tabular}

Table 3. Pearson Correlation coefficient between independent and dependent variable

The bold factor is the most influential factor (with the largest absolute value in the same flight).

With the computed Pearson correlation coefficients for $\mathrm{PM}_{2.5}$, it is inconclusive to say that there is a linear correlation between the observed parameters. Note that $\mathrm{PM}_{2.5}$ concentration decreases as the height increases but with an exception in the height interval of 200 to $280 \mathrm{~m}$ due to changes in the atmospheric conditions. To further examine this, the researchers computed for the correlation between $\mathrm{PM}_{2.5}$ concentration and the meteorological parameters using the flight cycles of the UAV. The height intervals shown in Table 4 were based on this flight cycles. 
Generally, the correlation coefficients increased for all the observed parameters when divided into height intervals. From the above table, temperature is the most influential factor which is noted to stay positively correlated with $\mathrm{PM}_{2.5}$ concentration from 0 to 200 meters then negatively correlated from 200 to 280 meters which shifted to positive correlation from 280 meters and up. Same correlation trend can be observed with variable pressure. The opposite happened for variables relative humidity, wind speed, and height in which the variables were negatively correlated with $\mathrm{PM}_{2.5}$ concentration except for height interval 200 to 280 meters.

\begin{tabular}{|r|r|r|r|r|c|}
\hline PM2.5 & $\begin{array}{c}\text { Tempera } \\
\text { ture }\end{array}$ & $\begin{array}{c}\text { Relative } \\
\text { Humidity }\end{array}$ & Pressure & Height & $\begin{array}{l}\text { Wind } \\
\text { speed }\end{array}$ \\
\hline $0-80$ & $\mathbf{0 . 8 1 7 1}$ & -0.7890 & 0.6826 & -0.6846 & -0.9648 \\
\hline $80-120$ & $\mathbf{0 . 7 5 3 7}$ & -0.6699 & 0.5626 & -0.5650 & -0.4579 \\
\hline $120-160$ & 0.0408 & 0.0477 & -0.1602 & 0.1637 & -0.1031 \\
\hline $160-200$ & $\mathbf{0 . 7 6 6 7}$ & -0.6098 & 0.6637 & -0.6618 & -0.0220 \\
\hline $200-240$ & $\mathbf{- 0 . 7 1 0 9}$ & 0.6510 & -0.3429 & 0.2959 & 0.0307 \\
\hline $240-280$ & $\mathbf{- 0 . 6 3 3 0}$ & 0.5031 & -0.0922 & 0.0869 & 0.0748 \\
\hline $280-320$ & $\mathbf{0 . 8 4 4 8}$ & -0.5994 & 0.5573 & -0.6207 & -0.6207 \\
\hline $320-360$ & $\mathbf{0 . 6 3 3 2}$ & -0.6162 & 0.2063 & -0.2050 & -0.5303 \\
\hline $360-400$ & $\mathbf{0 . 8 6 0 7}$ & -0.7534 & 0.0558 & -0.0695 & 0.0964 \\
\hline 400 and & $\mathbf{0 . 8 4 4 4}$ & -0.8240 & 0.3297 & -0.3423 & -0.2976 \\
\hline up & & &
\end{tabular}

Table 4. Pearson correlation coefficient between independent and dependent variable for different height intervals

The bold factors are the most influential factors (with the largest absolute value in the flight).

Relative humidity is the second most influential factor based on the correlation coefficients. Pressure and height correlation coefficients show almost the same values but of opposite signs. This may imply that these two variables have equal effects on the pollutant concentrations. Variable wind speed has the least correlation coefficients among the independent variables.

To determine the strength of linear relationship between the independent variables during the flight, Pearson correlation analysis was also used. Table 4 shows the Pearson correlation coefficients of independent variables. As shown in the table, Relative Humidity has a strong relationship with Temperature with the correlation coefficient of -0.9963 , while air Pressure has even higher relevance to Height with the correlation coefficient of -0.99998 .

\begin{tabular}{|c|c|c|c|c|c|}
\hline & Temp & $\begin{array}{c}\text { Relative } \\
\text { Humidity }\end{array}$ & Pressure & Height & $\begin{array}{c}\text { Wind } \\
\text { speed }\end{array}$ \\
\hline Temperature & - & $\mathbf{- 0 . 9 9 6 2 9}$ & 0.99423 & -0.9943 & -0.18848 \\
\hline $\begin{array}{c}\text { Relative } \\
\text { Humidity }\end{array}$ & & - & -0.9925 & 0.99291 & 0.18186 \\
\hline Pressure & & & - & $\mathbf{- 0 . 9 9 9 9 8}$ & -0.15406 \\
\hline Height & & & & - & 0.15377 \\
\hline Wind speed & & & & & - \\
\hline
\end{tabular}

Table 5. Pearson correlation coefficients of independent variables

The bold factors are the most influential factors (with the largest absolute value in the flight).
Pressure has also high correlations with temperature and relative humidity with coefficients of 0.9942 and -0.9925 , respectively. Height has also a high correlation with temperature and RH but of opposite signs as compared with pressure. Wind speed has the lowest correlation coefficients among the independent variables. These high correlations between the independent variables have resulted to multicollinearity between the variables affecting the regression model was which was discussed in the succeeding sections.

The following figure shows the vertical profiles of the independent variables. The figures only reflect how the independent variables were correlated in the correlation analysis. Moreover, Table 6 shows the Average values of every observed parameter for every height interval. This was the data used in showing the $\mathrm{PM}_{2.5}$ concentration behavior with respect to the independent variables as well the vertical profiles of the independent variables.

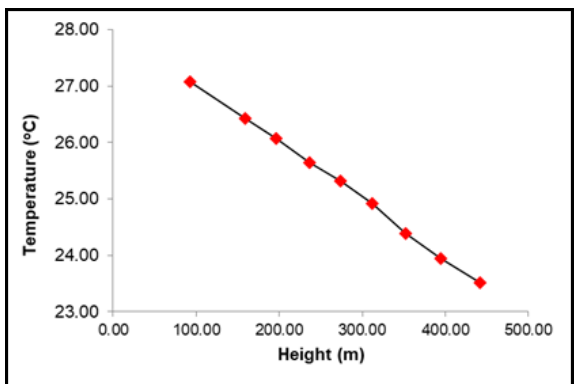

Figure 19. Vertical profile of temperature during the flight

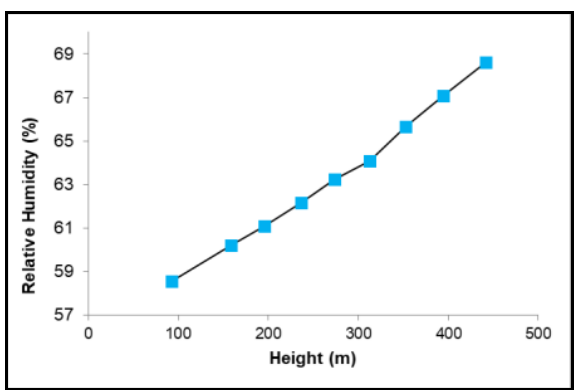

Figure 20. Vertical profile of relative humidity during the flight

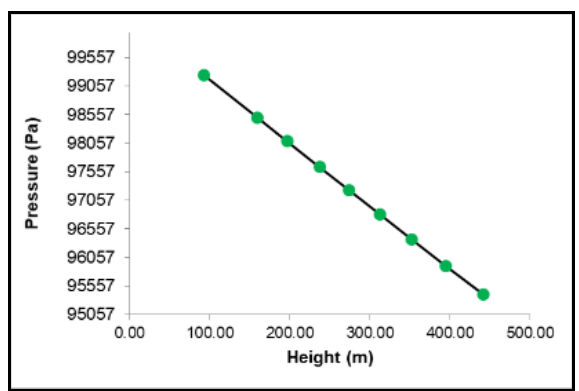

Figure 21. Vertical profile of pressure during the flight

The following figure, Figure 22, shows a sudden drop of 12.48 $\mathrm{kph}$ in the wind speed values around 300 meters with no apparent changes in other parameters. This may be explained by the wobbling of the UAV or the turbulence experienced by it due to unstable atmosphere. This sudden drop of wind speed in the height interval 200-280 m may explain the increase in the $\mathrm{PM}_{2.5}$ concentration in that interval (shown in Figure 11 and Figure 13). 


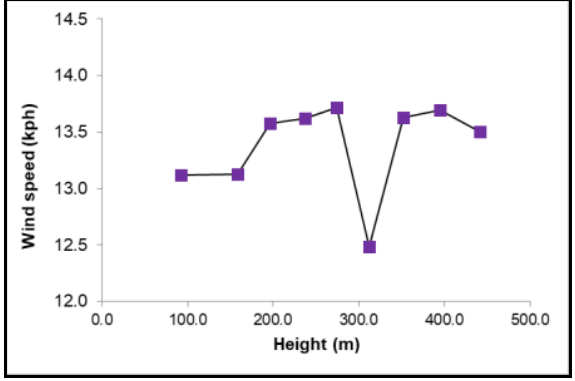

Figure 22. Vertical profile of wind speed during the flight

\begin{tabular}{|c|c|c|c|c|c|c|}
\hline Flight cycle & Height $(\mathrm{m})$ & $\begin{array}{c}\text { Temperature } \\
\left({ }^{\circ} \mathrm{C}\right)\end{array}$ & $\begin{array}{c}\text { Relative } \\
\text { Humidity } \\
(\%)\end{array}$ & $\begin{array}{c}\text { Pressure } \\
(\mathrm{Pa})\end{array}$ & $\begin{array}{c}\text { Wind speed } \\
(\mathrm{kph})\end{array}$ & $\begin{array}{c}\text { PM2.5 } \\
\text { concentration } \\
\left(\mu \mathrm{g} / \mathrm{m}^{3}\right)\end{array}$ \\
\hline $80-120$ & 92.41 & 27.07 & 58.56 & 99252.6 & 13.12 & 6.61 \\
\hline $120-160$ & 158.63 & 26.43 & 60.21 & 98514.98 & 13.13 & 5.97 \\
\hline $160-200$ & 195.97 & 26.06 & 61.09 & 98098.88 & 13.58 & 5.35 \\
\hline $200-240$ & 236.68 & 25.64 & 62.17 & 97648.02 & 13.62 & 6.42 \\
\hline $240-280$ & 273.85 & 25.32 & 63.25 & 97238 & 13.72 & 7.68 \\
\hline $280-320$ & 312.42 & 24.92 & 64.09 & 96812.5 & 12.48 & 7 \\
\hline $320-360$ & 352.04 & 24.39 & 65.65 & 96376.05 & 13.63 & 6.94 \\
\hline $360-400$ & 394.61 & 23.95 & 67.08 & 95912.57 & 13.69 & 5.64 \\
\hline 400 and up & 441.35 & 23.52 & 68.63 & 95409.55 & 13.5 & 4.17 \\
\hline
\end{tabular}

Table 5. Average values of every observed parameter per flight cycle/height interval

The above table shows the values used to determine the graphs and vertical profiles shown in the previous sections. These values are average values of each parameter per flight cycle or height interval. The values per height interval were averaged to easily distinguish the trend that is existing between the variables. When the values are plotted, they show the same consistent trends with the above vertical profiles but they are too scattered to be recognized.

\subsubsection{Ordinary Least Squares}

In this study, the five parameters are set to be the independent variables, and $\mathrm{PM}_{2.5}$ concentration as the dependent or response variable. This step aims to get the regression equation that models the dependent relationship between these variables using the whole dataset. Thus, in this part, the over-all relationship will be modelled through the equations to be generated at each step.

Independent Variables: Height, Relative Humidity, Temperature, Wind speed, Pressure

Dependent Variable: PM 2.5 Concentration

Regression Equation:

PM2.5 = $9633+3.11$ Temperature +0.176 Relative Humidity 0.470 Wind speed -1.045 Height -0.0969 Pressure

Before relying on the regression equations, assumptions in Ordinary Least Squares should be verified. In running the regression, OLS is under assumptions that are used to derive the OLS estimators in the linear regression models.

\section{Normality of Errors or Residuals - Shapiro - Wilk Test}

A residual is the vertical distance between a data point and the regression line. Each data point has one residual. They are positive if they are above the regression line and negative if they are below the regression line. If the regression line actually passes through the point, the residual at that point is zero.

\begin{tabular}{lc}
\hline \multicolumn{2}{c}{ Shapiro-Wilk test (Residuals) } \\
\hline W & 0.996 \\
p-value (Two-tailed) & 0.420 \\
alpha & 0.05 \\
\hline \multicolumn{2}{l}{ Table 6. }
\end{tabular}

Test interpretation:

$\mathrm{H}_{\mathrm{o}}$ : The variable from which the sample was extracted follows a Normal distribution.

$\mathrm{H}_{\mathrm{a}}$ : The variable from which the sample was extracted does not follow a Normal distribution.

As the computed p-value is greater than the significance level alpha $=0.05$, one cannot reject the null hypothesis $\mathrm{H}_{0}$. Thus, it is safe to say that the assumption in the linear regression that the residuals are normal. We have met the assumption of normality of residuals.

\section{Test for Heteroscedasticity - Breusch-Pagan Test}

It is a systematic change in the spread of the residuals over the range of measured values. Heteroscedasticity is a problem because ordinary least squares (OLS) regression assumes that all residuals are drawn from a population that has a constant variance (homoscedasticity). It assumes that all error terms have the same variance and are not correlated with each other.

\begin{tabular}{cc}
\hline \multicolumn{2}{c}{ Breusch-Pagan Test } \\
\hline LM (Observed value) & 2.453 \\
LM (Critical value) & 3.841 \\
DF & 1 \\
p-value (Two-tailed) & 0.117 \\
alpha & 0.05
\end{tabular}

Table 7. Breusch-Pagan Test results

Test interpretation:

$\mathrm{H}_{\mathrm{o}}$ : Residuals are homoscedastic

$\mathrm{H}_{\mathrm{a}}$ : Residuals are heteroscedastic

As the computed p-value is greater than the significance level alpha $=0.05$, one cannot reject the null hypothesis $\mathrm{H}_{0}$. The risk to reject the null hypothesis $\mathrm{H}_{\mathrm{o}}$ while it is true is $11.73 \%$. Thus, we have met the assumption of constant variance of the residuals (homoscedasticity). Homoscedasticity describes that the error term, that is, the "noise" or random disturbance in the relationship between the independent variables and the dependent variable, is the same across all values of the independent variables.

\section{Durbin - Watson Test (Autocorrelation of Variables)}

The Durbin-Watson test statistic tests the null hypothesis that the residuals from an Ordinary Least-Squares regression are not autocorrelated. Autocorrelation means that the errors of adjacent observations are correlated. If the errors are correlated, then least-squares regression can underestimate the standard error of 
the coefficients. Underestimated standard errors can make the predictors seem to be significant when they are not.

The Durbin-Watson statistic (D) is conditioned on the order of the observations (rows). Minitab assumes that the observations are in a meaningful order, such as time order. Because of the dependence of any computed Durbin-Watson statistic on the data, exact critical values of DW statistic are not tabulated for all possible cases. Instead, Durbin and Watson established upper and lower bounds for the critical values.

The generated OLS regression equation shows the model using the five parameters (Temperature, Relative Humidity, Airspeed, Height, and Pressure) after doing the regression to check the DW statistic.

\begin{tabular}{lc}
\hline Durbin-Watson Statistic & 1.01882 \\
Lower bound $\left(\mathrm{D}_{\mathrm{L}}\right)$ & 1.80760 \\
Upper bound $\left(\mathrm{D}_{\mathrm{U}}\right)$ & 1.85129 \\
alpha & 0.05 \\
number of parameters $(\mathrm{k})$ & 5 \\
number of samples $(\mathrm{n})$ & 369 \\
\hline \multicolumn{2}{l}{ Table 8. Durbin-Watson Test results }
\end{tabular}

To get a conclusion from the test, $\mathrm{D}$ is to be compared with $\mathrm{D}_{\mathrm{U}}$ and $\mathrm{D}_{\mathrm{L}}$. If $\mathrm{D}>\mathrm{D}_{\mathrm{U}}$, no correlation exists; if $\mathrm{D}<\mathrm{D}_{\mathrm{L}}$, positive correlation exists; if DW statistic is in between the two bounds, the test is inconclusive. The significance level for the test is 0.05 .

According to the table, at $5 \%$ level of significance, with $n=369$ and $\mathrm{k}=5$ (number of parameters), the lower bound (DL) is 1.80760 and upper bound $(\mathrm{Du})$ of 1.85129. The displayed value for the Durbin-Watson statistic (D) is 1.01882. Since D < DL, positive autocorrelation exists.

\subsubsection{Stepwise Regression}

\begin{tabular}{ccc}
$\begin{array}{c}\text { Step } \\
\text { No. }\end{array}$ & Selected & Eliminated \\
\hline 1 & Relative Humidity & \\
2 & Pressure & \\
3 & Height & \\
4 & Wind Speed & \\
5 & Temperature & \\
6 & & Relative Humidity \\
\hline
\end{tabular}

The problem of autocorrelation shown in the previous test is being addressed in this type of regression. In Stepwise, there is a variable selection going on. At each step, each parameter/ independent variable is being evaluated to see if it should either be included or excluded in the model. The table below shows the variables being included at each step. Relative Humidity was the first variable that went through the evaluation, followed by the Pressure, Height, Airspeed, and Temperature. However, at the final step, Relative Humidity was eliminated in the process.

\begin{tabular}{cc}
\hline Term & VIF \\
\hline Constant &
\end{tabular}

\begin{tabular}{cc} 
Temperature & 102.53 \\
Airspeed & 1.17 \\
Height & $\mathbf{3 4 5 2 8 . 0 1}$ \\
Pressure & $\mathbf{3 3 8 2 4 . 0 9}$ \\
\hline 10. VIF Values in Step-wise Regression
\end{tabular}

Regression Equation:

PM2.5 = 9142 + 2.773 Temperature - 0.464 Airspeed 0.987 Height -0.0918 Pressure

It is evident in Table 10 that the parameters have high values of Variance Inflation Factor (VIF). In effect, having high VIF values is one of the signs of having a multicollinearity problem. As the name suggests, a VIF quantifies how much the variance is inflated. The standard errors, and hence the variances of the estimated coefficients are inflated when multicollinearity exists. In linear regression, predictors that are correlated with other predictors are signs of multicollinearity which has already been proven with the data sample in the correlation analysis, shown in Table 5. It occurs when the model includes multiple factors that are correlated not just with the response variable, but also to each other. In other words, it results when you have factors that are a bit redundant. This results into higher standard errors wherein significant parameters may be declared as not significant. It may be the case of the Relative Humidity after being eliminated in the Step-wise regression. This variable might be important in the model, but eliminated due to multicollinearity.

To address this, the variable with the highest VIF value should be eliminated in the next run of regression. In this case, height and pressure have the highest values. Since we do not know which factor contribute significantly more than the other yet, we can consider the correlation analysis. Correlation analysis quantifies the relationship between the meteorological parameters and the $\mathrm{PM}_{2.5}$ concentration thus this can be used to determine which factor has a better effect on the concentration in terms of linear relationship. Pressure has the lowest absolute value of correlation coefficient with 0.1310 compared to the absolute value of the coefficient of Height which is 0.2289 and to the other factors.

Moreover, since this study aims to determine the vertical distribution of $\mathrm{PM}_{2.5}$ concentration, the need to take into account the effect of Height is of utmost importance than adding Pressure. Additionally, Temperature and Relative Humidity have high correlation coefficients with Pressure which means that these two factors can already explain Pressure without the latter variable being included in the regression. These lead us to the decision of excluding Pressure in the next run of regression.

\subsubsection{Simple Linear Regression}

Independent Variables: Relative Humidity, Temperature, Wind speed, Height

Dependent Variable: PM 2.5 Concentration

Regression Equation:

PM2.5 $=96.0690+0.1495$ Temperature -1.5878 Relative Humidity -0.3587 Wind speed -0.0435 Height

The above equation is the new multiple linear regression excluding Pressure. The $\mathrm{R}^{2}$ value for the equation is 0.225 which means that $23 \%$ of the variability of the dependent 
variable $\mathrm{PM}_{2.5}$ is explained by the 4 explanatory variables In statistics, there is the "Principle of Parsimony", wherein we prefer the simplest model with the least assumptions and variables but has the greater explanatory power. After running all the tests, this model has the greatest explanatory power since it is consistent with the Correlation Analysis and in the literature in terms of the effect of meteorological parameters and $\mathrm{PM}_{2.5}$ concentration. This model shows that Relative Humidity has the greatest influence on the change of the $\mathrm{PM}_{2.5}$ concentration value, while Height has the least. Again, excluding Pressure in the regression does not mean that it is not significant to the dependent variable. As discussed, the effect of Pressure is already accounted in the other variables given the high correlation between the independent variables.

Also, having the problems of multicollinearity and autocorrelation, do not make the model invalid. The regression is still valid as Descriptive Statistic. Here, relationships are being described within the data sample only. We cannot generalize that the model for this sample is applicable to the whole population.

\section{CONCLUSIONS AND RECOMMENDATIONS}

\subsection{Conclusion}

In this study, UAV integrated with mobile monitoring sensors was used for collecting PM2.5 mass concentration data within the height of $500 \mathrm{~m}$ in a cylindrical path over Brgy. Hardin ng Rosas, UP Diliman, Quezon City. The study demonstrated that the customized sensor-carrying UAV is an effective and flexible tool for measuring PM2.5 concentration and vertical distribution. From the data acquired, the vertical distribution of a particulate matter using integrated PM 2.5 sensor and UAV was determined. The experiment shows that generally PM2.5 concentration decreases as the height increases with an exception in the height interval 200-280 meters due to a sudden change of atmospheric conditions. The vertical profile of the PM2.5 concentration is observed to be influenced by meteorological parameters. It is worth mentioning that the sudden decrease of wind speed in the height interval 200-280 meters may explain the increase in the PM2.5 concentration on the said height interval.

Also, the relationship between PM2.5 concentration and the meteorological parameters have been identified. From the correlation analysis conducted, PM 2.5 Concentration has a positive relationship with Temperature, thus, when temperature increases, PM2.5 increases. On the other hand, PM 2.5 Concentration has a negative relationship with Relative Humidity and Wind speed, thus, as Relative Humidity and Wind speed increases, PM2.5 decreases. A multiple regression model was developed to illustrate the effect of meteorological parameters to PM2.5 concentration. The coefficients show that Relative Humidity is the most important factor while Pressure is the least important.

\subsection{Recommendations}

Through this study, it demonstrates the potential of unmanned aerial vehicle (UAV) integrated with mobile sensors to observe three-dimensional air pollutant concentrations. However, there are still limitations to be improved for future studies. This study further recommends reviewing the flight path and configuration having less interval in order to have more data points and longer flight duration. For further studies, it is recommended to have different flights over the different periods of time in a day and several flights with various pollution events, to have comparisons in different site conditions more flights in different seasons with various weather conditions should be conducted to fully understand the vertical distribution patterns of different pollutants in different meteorological conditions.

\section{REFERENCES}

Adel, R. (2017). Manila named 10th most stressful city in the world | Philstar.com. [online] philstar.com. Available at: https://www.philstar.com/headlines/2017/09/14/1739115/ manila-named-10th-most-stressful-city-world [Accessed 19 Jan. 2018].

Bates, T. S., Quinn, P. K., Johnson, J. E., Corless, A., Brechtel, F. J., Stalin, S. E., Burkhart, J. F. (2013). Measurements of atmospheric aerosol vertical distributions above Svalbard, Norway, using unmanned aerial systems (UAS). Atmospheric Measurement Techniques, 6(8), 2115-2120. https://doi.org/10.5194/amt-6-2115-2013.

Baxter, R. A., \& Bush, D. H. (2014). Use of Small Unmanned Aerial Vehicles for Air Quality and Meteorological Measurements, 19.

Department of Environment and Natural Resources (2005).

"National Air Quality Status Report: 2003-2004". DENR. Quezon City, Philippines.

Department of Environment and Natural Resources (2012).

"National Air Quality Status Report: 2010-2011". DENR. Quezon City, Philippines.

Department of Environment and Natural Resources (2015).

"National Air Quality Status Report: 2008-2015". DENR. Quezon City, Philippines.

Department of Environment and Natural Resources (2017). Air

Pollution: a public health concern in the Philippines. [online] denr.gov.ph. Available at: http://www.denr.gov.ph /news-andfeatures/latest-news/3295-air-pollution-a-public-health-concernin-the-philippines.html

Health.ny.gov. (2018). Fine Particles (PM 2.5) Questions and Answers. [online] Available at: https://www.health.ny.gov/environmental/indoors/air/pmq_a.ht m [Accessed 20 Feb. 2018].

Medium. (2016). The Use of Drones in Measuring Air Quality, Pollution \&Treatment Controls. [online] Available at: https://medium.com/@UAVLance/the-use-of-drones-inmeasuring-air-quality-pollution-treatment-controls6d4ee4522c8c [Accessed 20 Jan. 2018].

Miguel, C. (2013). DENR sets standards for fine particle pollutants. [online] Denr.gov.ph. Available at: http://denr.gov.ph/news-and-features/latest-news/1267-denrsets-standards-for-fine-particle-pollutants.html [Accessed 20 Feb. 2018].

Miguel, C. (2017). Air pollution: A public health concern in the Philippines. [online] Denr.gov.ph. Available at: http://www.denr.gov.ph/news-and-features/latest-news/3295air-pollution-a-public-health-concern-in-the-philippines.html [Accessed 19 Jan. 2018]. 
Peng, Z. R., Wang, D., Wang, Z., Gao, Y., \& Lu, S. (2015). A study of vertical distribution patterns of PM2.5 concentrations based on ambient monitoring with unmanned aerial vehicles: A case in Hangzhou, China. Atmospheric Environment, 123, 357369. https://doi.org/10.1016/j.atmosenv.2015.10.074.

Roces, A. (2002). Metro Manila air pollution exceeds tolerable level | Philstar.com. [online] philstar.com. Available at: https://www.philstar.com/opinion/2002/09/10/175428/ metromanila-air-pollution-exceeds-tolerable-level [Accessed 19 Jan. 2018].

Romualdez, B. (2014). Metro Manila pollution worse than ever | Philstar.com. [online] philstar.com. Available at: https://www.philstar.com/business/2014/11/25/1395497/ metromanila-pollution-worse-ever [Accessed 19 Jan. 2018].

Villa, T.F.; Gonzalez, F.; Miljievic, B.; Ristovski, Z.D.; Morawska, L. An Overview of Small Unmanned Aerial Vehicles for Air Quality Measurements: Present Applications and Future Prospectives. Sensors 2016, 16, 1072.

Watts, A.C.; Ambrosia, V.G.; Hinkley, E.A. Unmanned Aircraft Systems in Remote Sensing and Scientific Research: Classification and Considerations of Use. Remote Sens. 2012, 4 , 1671-1692. 